University of Wollongong

Research Online

January 2020

\title{
Assessing Blockchain Technology application for freight booking business: a case study from Technology Acceptance Model perspective
}

Wee Kwan Albert Tan

Balan Sundarakani

University of Wollongong, balan@uow.edu.au

Follow this and additional works at: https://ro.uow.edu.au/dubaipapers

\section{Recommended Citation}

Tan, Wee Kwan Albert and Sundarakani, Balan: Assessing Blockchain Technology application for freight booking business: a case study from Technology Acceptance Model perspective 2020, 1-22.

https://ro.uow.edu.au/dubaipapers/1178 


\section{Journal of Global Operations and Strategic So}

\section{Assessing Blockchain Technology application for freight booking business: A case study}

\begin{tabular}{|r|l|}
\hline Journal: & Journal of Global Operations and Strategic Sourcing \\
\hline Manuscript ID & JGOSS-04-2020-0018.R2 \\
\hline Manuscript Type: & Research Article \\
\hline Keywords: & $\begin{array}{l}\text { Blockchain, Smart Contract, Shipping industry, Freight consolidation, } \\
\text { Global Supply Chain, Process design }\end{array}$ \\
\hline Data Type: & Qualitative \\
\hline \multicolumn{2}{|l}{} \\
\hline
\end{tabular}




\title{
Assessing Blockchain Technology application for freight booking business:
}

\section{A case study from Technology Acceptance Model perspective}

\begin{abstract}
Purpose

Blockchain technology adoption has been growing than even before in all industry verticals. This research aims to evaluate the use of Blockchain technology in improving the business efficiencies of the freight consolidation processes. Our research critically examine the challenges faced by a global shipping company that offer freight consolidation businesses and explore the use of Blockchain technology to enhance the competitiveness and sustainability of freight booking operations.
\end{abstract}

\section{Design/methodology/approach}

The research applies an Inductive case study approach by taking into consideration of an organisation involved adopting Blockchain as a technology to improve the efficiencies of the logistics frieght booking. As the case is explorative in nature, the research aim to unearth the complex blockchain adoption phenomenon in the industry as the technology is very nascent at present. The research is primarily grounded on Technology Acceptance Model (TAM) theory.

\section{Findings}

The research finds that blockchain technology supports solving many issues and inefficiencies of global shipping operations but there are some barriers that they need to overcome. The research provides a framework and recommendations for global company to consider when considering Blockchain technology for implementation. Our research finding shows that smart contracts can be set up at critical points along with the shipment route namely the storage, customs, carrier, transporters and consignee stage to ensure greater security and transparency.

\section{Research limitations/implications}

The research provides recommendations to key stakeholders involved in freight forwarding segment of logistics industry while adopting blockchain technology. Apart from the methodological limitation of the research, the research is limited to Singapore in terms of geographical coverage. 


\section{Originality/value}

This case study is the first of its kind to examine the use of blockchain to explore the adoption in logistics Industry in Singapore and perhaps worldwide.

Keywords: Freight consolidation, Global Supply Chain, Blockchain, Smart contract, Cargo consolidation, Technology Acceptance Model

Paper type: Research paper

\subsection{Introduction}

Blockchain technology adoption has been growing than even before in all industry verticals, however the rate of adoption is still nascent in its current stage. According to IBM (2017), the annual turnover of the international shipping industry is around $\$ 4$ trillion with around $80 \%$ goods being transported by the ocean vessel. Most of the delivery activity such as shipment and delivery tracking, estimated time of delivery, seeking customer sign-off and from the port and custom officers' notifications are all manual paper processes (Lambrou et al. 2019). Interestingly, the annual cost of global trade is around \$1.8 trillion which includes saving of around 10\% from some well managed global trade processes. According to Jensen et al. (2019), overall cost of the total trade in the international shipping industry has witnessed an increase in trend due to many challenges. In the year 2018, 13.5 trillion employees have been recruited in the shipping industry to handle $\$ 4$ trillion value of goods (Liu et al. 2018). With the increase in magnitude of cost of shipping, increasing the risks of the industry, reducing the number of incidents and consequently reducing costs are still relatively complicated and yet to be standardized in the shipping industry (Lessa and Bulut, 2020). It is evident that investing in such emerging technology would create competitive advantage in firm's performance (Behl, 2020; Pandey et al. 2020)

\subsection{Research Significance}

In the modern shipping industry operations, there is a need to reduce the cost and time involved in shipping of goods along with reduction in paper work. With the implementation of new processes, the shipping industry can achieve seamless process efficiency and thereby reduction the cost and improving the performance outcome. According to Goldby (2019), once the supply chain barriers 
reduces and the transportation process becomes transparent and digitalized, there will be around 15\% rise in the overall trade which shall also result in economic development of trade services. On the other hand, Liner freight comprised of around $67 \%$ of the world trade in the recent past decade (Lambrou et al. 2019). Globally, shipping industry's main goal is to reduce the time of delivery along with reducing the time taken for information pertaining to the container to reach the port and sail efficiently (Riley, 2017).

As stated by Tirschwell (2018), the shipping business is highly fragmented and therefore hugely dependent on tradition-based paper work. Besides the legal contract on paper, a lot of data and information have been shared digitally by way of electronic data interchange (EDI), which seemed to be a 60 -year-old technique. As a method of transition, White (2018) said that by setting up the API based technology system, there will be much more transparency and visibility to all the elements of the supply chain. While digitalization helps to reduce paper work and improve documentation that can enable parties across boundaries to share documents freely and quickly using the digital platform (Vogt and Paul, 2011; Jensen et al. (2019)).

From there on, many issues also occur such as handling the paperwork, affirming cargo providence, ensuring cargo integrity and wasteful and costly processes. Though managers in the shipping industry expects more control on the cost and minimize the ill-effect of the process delay, the barrier to digital transformation and modern technology adoption seems to be ever-growing (Papathanasiou et al. (2020). While traditional manual tracking-based paper work results on inefficient control, scope of fraud and forgery along with failures and therefore can lead to many disputes, this can be achieved by adopting the digital transformation by means of blockchain integration (Queiroz and Wamba, 2019)

\subsection{Research Problem Statement}

While selecting the right blockchain kit for adoption, there seems to be a confusion among the minds of shippers, carriers and other stakeholders existing in the shipping eco-system (Jensen et al. 2019). There are questions related to governance and scalability of blockchain tools, because digitalization of the industry exposes to the threat of cyber-crime and cyber thefts (Papathanasiou et al. 2020). Moreover, there are many apprehensions about privacy and security of data in digital environment as is being promised (Kamble et al. 2019). "Is Blockchain Technology better than paper based or electronic bill of lading, the question being raised by stakeholders often?" Which is still remain not researched sufficiently (Queiroz and Wamba, 2019; Kamble et al. 2019). 
While, there are many issues related to removal of third parties and banks in minimising costs of transaction due to lesser needs of trust in blockchain which is relatively new technology (Papathanasiou et al. 2020). The use of Smart contracts as an alternative to current bill of lading and electronic bill of lading which can make payments immediately of fulfilment of conditions still needs to be understood by many stakeholders (Kamble et al. 2019). Blockchain at this stage is posing more questions than finding solutions to improve container transport in shipping industry. Therefore, this research is aimed to understand the current process in freight booking and consolidated industry and how smart contract and blockchain can significantly improving efficiencies in this industry. More specifically, the research is aimed to examine how a global cargo consolidation company, ECU Worldwide (ECU) plans to migrate their current process using Blockchain technology as a case study research.

\section{Literature review}

\subsection{Shipping Industry}

As the global trade gravity has shifted towards the emerging market, China has taken the gravity of global manufacturing in 2012 with about $22 \%$ of world manufacturing output were attracted in (Davies and Raskovic 2017). Likewise, India, Brazil and Russia drive the manufacturing and trade activities with other emerging economies and thereby enhance the level of trading of goods in the global market. These developments have shifted the world trade of goods including the shipping industry pattern (Clott et al. 2020). Thus, the ocean shipping industry became more prevalent mode of transportation by the ability to practically perform any trade all over the world. The international seaborne trade has gone up sharply over the last 40 years for not only dry cargo materials but also for bulk cargo, containerised products and other oil and gas commodities (Clott et al. 2020). Although there are seemingly no limits to the potential increase of any commodities with the seaborne trade, the increase in trade activities are phenomenal (Jensen et al., 2019). Figure 1 illustrates, the total cargoes transported by sea freight have increased continuously from only 2605 millions of tonnes in 1970 to 10287 millions of tonnes in 2016 (UNCTAD 2017). Albeit shipping industry has its legacy, the fundamental trait of this industry remains the volatility associated with the trade as the demand and supply are hard to predict and therefore the face of uncertainty. 


\subsection{Role of Technology in the Shipping Industry}

Because of globalization, the adoption of new technologies is necessary to catch up with speed of changes happening in the global market. The state-of-the-art technologies are implemented everywhere in every industry to make the work more efficient, faster and easier. According to Kavussanos and Visvikis (2006), shipping industry is the collection of many actors from different platforms which has a very complex supply network chain who are interacting each other directly and indirectly for processing the shipment work across the world. Many technological advances have been installed in the shipping industry so far. These days, Shippers can electronically send the export declaration to the Customs at the port of destination through the Automated Export System (AES). Earlier, Fylaktopoulos et al. (2016) made use of the cloud technology in the context of shipping industry to create a software service platform. By using this platform, the data analysis become easier and processing of activities help to reduce the limitations of transportation. In this space, Kouvelis and Li (2013) suggested an international freight forwarder system to control all the documentation processes. However, the aforementioned systems are limited to a particular industry situation and could not be scaled up due to their limitations (Tan et al. 2018). Over the last two decades, majority of risks causing the severity of cargo damage in container shipping has come from the licensed operators and the size of the ships. According to the study of Tseng et al. (2012) "container data setting errors" is considered to be the top reason for the risk happen with the reefer container contains aquatic products. Hence, the challenges, as well as the risk in conducting the kind of business related 
to the container, need to be identified soonest and all the related companies must aware of these risks in conjunction with their influence on the shipping operations.

\subsection{Lack of Trust in Shipping Industry}

Recent pandemic of COVID 19 has created enormous uncertainty in the face of logistics and supply chain network processes (Ivanov, 2020). In order to become more resilient in the modern supply chain delivery, 'trust' and 'transparency' place a dual role for business recovery (Mann, 2020). While examining the shipping industry, the trust between the importer and exporter lies in a lowest level during the shipment process (Banker, 2016). In reality, Importer tries to delay the payment as long as possible whereas the exporter tries to ask for the payment as early as possible. Both parties need money for the smooth processing of their operations and to avoid any kind of distractions. The level of trust is thus very weak between the importers and exporters (Chryssochoidis \& Theoharakis, 2004). Having discussed, trade finance work in a way that the money has been paid by the exporter in a letter of credit (LoC) being issued and signed by all relevant parties (Sun et al. 2016). However, the current tools for trade finance are costly and rely heavily on the documentary proofs (Sun et al. 216). While transactions, collections of documents are transferred during the shipment process like bill of lading $(B / L)$ which contains the information of about the goods and services. In the next step of the shipment process, the goods are unloaded by the shipping agents at the port premises, which is a risky task. Shipping process may get delayed because of this inconsistent delivery methods and the goods are being dumped in the garages for longer period (Anders and Jorgen, 2017). This activity adversely impacts on the quality and performance of shipping process and thereby creating problems between the stakeholder's trust which further increases the complexity of supply chain management. Failure in retrieving reliable information on time, cost, the invisibility of goods in delivery management, emergence of major shipping bottlenecks, lack of work process in the inventory management system are some of the major factors which extend the transit time of the goods. In many of the shipping activities, hitherto, there is no proper digitalization of papers which leads to delay in transport of goods in the shipment domain (Riley, 2017).

\subsection{Information sharing in the shipping industry}

In fact, one of the major concerns existing in the supply chain of port logistics management is the 'lack of information sharing' of within and between the organizations (Razavi and Iverson, 2006). In order to overcome this issue, there is a need of trusted network systems which enable the individual information sharing with certain security norms. Information leakage is also a major issue associated 
with the information processing in supply chain partners. The confidentiality of information should be properly evaluated and most of the companies need to make assurance in the information exchange among supply chain partners is highly confidential (Fei, 2011). This trust in the confidentiality of information increases the bonding between the partners in the shipping process.

In assuring trust in the shipping industry activities, the role of trust among intermediaries such as freight consolidators are very important (Anders et al. 2017). They are getting profits in way along with ensuring the confidentiality of the information like certifying the goods quality and safety, and various measures for financing measures. Trusted intermediaries help to reduce the transportation cost and other processing charges, asymmetry in information exchange and different kinds of uncertainties with high degree of bargaining capability (Tan \& Thai, 2014). There should be an ethical way of trust between all shipping parties which are essential for perceiving the relationship while sharing the information (Fei, 2011). It could be argued that the relationship trust could be enhanced by having transparency and thereby the overall performance outcome could be enhanced (Anders et al., 2017). All the parties should be enabled by the solution to draft in electronic documents that are accepted internationally like electronic Bill of ladings (e-BoLs), invoices, and certificates of origin, warehouse warrants and other supporting documents that reflects the norms and standards of the wide industry (Anders et al. 2017). Due to the number of different parties' involved activities such as heterogeneity in customs, terminal operators, cargo forwarders, manufacturers, banks involved in each transaction, neutrality needs to be ensured by the service provider to avoid any irreconcilable circumstances among the parties involved (Takahashi, 2016).

\subsection{Role of blockchain in freight consolidation}

Blockchains are the distributed ledgers which stores makes a permanent and shared document for each transaction related to a particular asset and there by establishing an unbreakable trust among the parties (Brody, 2017). Distributed ledger technology is an incorruptible and irrevocable collection of data enclosed, shared in an encrypted database (Wright, 2015). Thus, the blockchain is distributed ledger which can be audited and evaluated by anyone but cannot be changed by no one. Application areas of blockchain technology are tracking of assets, monitoring of assets, processing and communication of long-term contracts (Wright, 2015). Blockchain can act as an interaction between the consenting parties without depending on a centralized organization like bank for managing the work process (Nakamoto, 2008). The creation of blockchain and Internet of Things (IoT) has brought back a new threshold for the shipping industry in terms of setting new standards and improving 
operational performance, however the implementations are still very nascent in the current stage (Clott et al. 2020).

The smart contract term has been introduced since 1994 by Nick Szabo and is defined as a computerized transaction protocol that will be performed when its terms and conditions are met (Christidis and Devetsikiotis, 2016). In technical terms, the smart contract contains the terms and conditions as the traditional contract has but it converts such terms into code and will be executed automatically. Despite being introduced more than 20 years ago, the utilization and dissemination of smart contract is only becoming popular recently, mainly because it accompanies with the advanced technology (Papathanasiou et al. 2020). Many research and studies have taken smart contract into account and come up with the conclusion that the smart contract is indeed a computer program set up to follow the conditions and will automatically validate and execute the conditions (Clott et al. 2020, Papathanasiou et al. 2020). The smart contract is written under the code that is the key of transaction and will be automatically enforced by another code (Badzar, 2016). However, Swan (2015) reiterated that the main characteristics of smart contract are autonomy, self-sufficiency and decentralization.

When the smart contract system aspects combined with blockchain, they create a transformative use of technological change in the shipping industry. Distributed ledger technology not only is used to record trigger events abut also to verify the smart contract's execution (McLean and Deane-Johns, 2016). Smart contract utilizes blockchain to execute obligations when certain conditions are met in the automatically and secure way (Levy, 2017). Since the blockchain technology includes data and computer code, it is more advantageous to implement smart contract because it can digitize procedures that depend largely on regulatory paperwork or need the amount of human administration. This combination mitigate the common risks happened by manual interventions (Guo and Liang 2016; Weber et al. 2016). On the other hand, the smart contracts carry out specific actions when predefined conditions are met. The automation characteristic of this system makes smart contract suitable for procedures in shipping industry in general by reducing the bureaucratic complexity and the intervention of human in any transaction.

Thus, the application of Blockchain technology with smart contract has the potential to transform and make freight booking more transparent in the same way the Internet changed in the past (Koeppl and Kronick, 2017). It is therefore a research gap to investigate the adoption of this transformative technology as more businesses are supportive of the need to have a shared secured ledger that establishes accountability and transparency while streamlining their freight sourcing processes with the view of increasing their trade with other countries. 


\subsection{Challenges in adopting Blockchain technology}

The jurisdictions around the world are not completely adopted or not yet accepted the blockchain system for the shipping industry (Lubowe and McDermott, 2016). The supply chain participants wish to use this kind of technology in trading and shipping services so that a universal adoption system should be achieved. For managing the efficiency of supply chain management system, data identification system plays a vital role in sharing the information among various supply chain networks of the world efficiently and accurately (Tan et al. 2018).

Earlier, IBM wanted an effective system standard for enhancing their work process collaboration and interdependency in the supply chain networks (Silina, 2012). The needs of global standards are needed by most of the global companies and stakeholders but still there is a confusion regarding the confidentiality of data exchange. However, carriers, port authorities and forwarders, are not having an appropriate back-end system to connect to the modern blockchain technology (Stake and Robert, 2006). Further, the IBM and Maersk even built a Hyperledger fabric which is under experimental use between trading partners, government authorities and logistic companies to boost the efficiency of blockchain as a digitization solution in the commercial trade (Bavassano et al. 2020).

However, there are potential challenges existing for this technology adoption in the shipping industry. It will take more than one entity in a supply chain to know the value in using blockchain when the adoption becomes seem-less with an end-to-end integration.

The first challenges when applying blockchain not only in the shipping field but in any field is the unpredicted integration obstacles when inserting a new technology into the established supply chain systems (Mougayar, 2016). Blockchain is a complex process and need the cooperation of every party involved. Although a higher degree of decentralization of this technology for tracking shipments, argued that it concentrates power in a handful of entities (Popper and Lohr, 2017).

Secondly, the financial risk is obviously the top consideration in the shipping industry (Wang et al. 2014). Applying blockchain in shipping context requires an increase in the role of the legal department expertise. It is imperative to have more experienced specialists in cryptocurrency space and other types of crypto assets which is the basic foundation of blockchain. Any company must be well-prepared about the blockchain literacy before embarking on this technology.

Thirdly, when participate in business in shipping industry, there are many parties from diverse countries involved. However, in some countries, there are seemingly limits to the potential use case from blockchain and not all countries are willing to take part in blockchain-based solutions. 
Especially for partners who locate in developing or least developed countries where they are still not ready for blockchain adoption. But it is necessary to have their participation to optimize the full potential of blockchain in shipping industry (Kshetri 2018).

Last but not least, the privacy leakage is among the most concern issue. Although many studies indicate that blockchain is safe in every aspect, some studies predict that blockchain still hard to entirely ensure the transactional privacy and create more opportunities for hackers. A shared ledger system like blockchain can open a gate that may leak the user's information (Barcelo 2007; Kshetri 2018; Meiklejohn et al. 2016). The more technology is, the better security system is required.

To approach these challenges thoroughly, it is necessary to fully understand the end-to-end adoption procedure of the shipping container industry. The above research gaps lead to the desirable motivation to conduct this research study. Therefore, this research study design is based on an explorative case study method as discussed in the proceeding section.

\section{Research Methodology}

The main goal of this study was to examine how Blockchain technology can overcome current issues in global cargo freight booking. It is evident that a case study research investigates a contemporary phenomenon such as Blockchain in its real-life context (Yin, 2014), so that existing theories might be taken up to gain a first insight into the phenomenon under study. Case studies can be used for different purposes. Earlier, Yin (2014) distinguished three types of case studies:

- An exploratory case study is aimed at defining the questions and hypotheses of a subsequent study (not necessarily a case study) or at determining the feasibility of the desired research procedure,

- A descriptive case study presents a complete description of a phenomenon within its context, and

- An explanatory case study comprises data bearing on cause-effect relationships that explaining how events happened.

In this research, we employ the second type of case studies method proposed by Yin (2014) and to focus on a global shipping company called, ECU in detail as there are not many such case studies available in the blockchain space at the time of our research. In the case study approach, Focus group interview is conducted with key country managers from ECU worldwide, by using semi-structure questionnaire in 2019 as depicted in Appendix A. The answers from each manager is compiled and sent to the senior management for verification and validation. The usage of evidences from several 
sources are collected as a recommended best practice for logistics researches in complex areas that have not been substantially exploited (Stake, 2006). The analyses of these data help us to propose a conceptual framework that will answer the research question of "How can blockchain help to address the current inefficiencies faced in the freight consolidation businesses?".

\subsection{ECU Worldwide - Case study}

Founded in 1987 at Belgium, ECU Worldwide (ECU) is a global leader in NVOCC services. The company has brought in several innovations in LCL (less than container load) and set several benchmarks in the industry over the last 2 decades. Earlier, Allcargo Logistics Ltd., India's largest integrated logistics solutions provider in private sector, acquired the company in 2006 which resulted in further efficiency of their operations. In May 2016, the company is rebranded as ECU Worldwide and consolidated their global presence by bringing all the offices under a single name to denote a well-knit offices and highly coordinated operations (ECU worldwide, 2020).

As more countries are industrializing and manufacturing sectors are expanding their businesses, they would normally outsource their logistics requirements to be handled by third party logistics providers. Therefore, the expected demand to ship their cargoes were expected to grow, ECU Worldwide was experiencing an annual growth of 7 to 8 percent from 2010 onward.

Led by a centralized management team, it has employed more than 300 staffs worldwide and have offices in 160 countries, offering LCL (Less than Container Load) and FCL (Full Container Load) services across the globe. The company provides wide variety of value- added services and logistics solutions have enable them in handling and transporting complex cargo for worldwide customers.

The vision for the company is "To be the global leader in our business, through customer delight by innovations, agility and sustainable business model." And the company COO quoted that "ECU Worldwide had grown from a small SME to be one of reputable LCL providers in the world over last thirty years". As a result of horizontal integration, ECU has evolved from LCL business, to also venture into related industry in the logistics area, such as transportation, warehousing and distribution.

Presently, ECU head office is based in Mumbai, India but its online system can be accessible anyway in the world to provide booking and tracking services for their customers. Over the years in the business, ECU has invested heavily on new technologies to upgrade their systems to meet the customers growing demands for better visibility and ease of doing business. 
"We are glad to share that the entire network is on same Information Technology (IT) platform, which makes the operations more uniform and also offering customers similar experience in service across the world" as commented by the COO.

\subsubsection{Nature of the freight consolidation industry}

Competition in this industry is extremely high and the business is quite fragmented serving two different markets, namely local forwarding companies and global forwarding companies such as DHL, Kuehne +Nagel, DB Schenkers, Maersk etc., Local forwarders focuses on helping their clients to obtain lowest possible freight rates (sometimes with rebates) and higher destination charges (DLC - destination lading charges), while the global forwarders have a balanced approach to keep the DLC lower, so that the consignees are not upset with any inconvenience caused.

However, LCL business modus operandi is quite different from the FCL business. While FCL operations and costing are determined based on the demand and supply, LCL business costing is subjected to the client's requirement. For instance, if clients prefer to have lower ocean freight and higher destination charges, arrangement to be made to their needs. Customers are looking for better shipment predictability and lower inventory holding costs which would expect ECU to extend their logistics services beyond freight consolidation. As a result, ECU has expanded its businesses to include warehousing and transportation services.

ECU Worldwide has a fair share of business from both local forwarders and global forwarders. ECU Worldwide, with its close partnership with major shipping lines have a competitive advantage over the smaller operators coupled with their network strength (coverage, single identity), visibility and reliability. But they are faced with niche local operators, who can offer extremely low rates, given their low-cost operations. 
Figure 2: Organization structure of ECU Worldwide in 2018 (Source: ECU)

\subsection{Company Structure}

ECU Worldwide had an organization structure as shown in Figure 2. The COO of APAC region is based in Singapore and each country manager reports to the Regional Heads (South East Asia and North Asia). At the country level, ECU has branch managers, product managers (for FCL and LCL) and they have dotted line reporting to the regional product heads, which are responsible for strategies development and business development for their regions. The two main departments in a forwarding business are the import and export departments while other supporting functions such as Finance, Human Resource, Administration, and Information Technology help to ensure smooth operations.

\subsection{Import Department}

Import operations team is responsible for managing two products, which are LCL and FCL. For LCL operations, team has the following responsibility (see Appendix B).

1. Receiving the pre-alert documents of the expected consolidation container. 
2. Checking the document for correctness, and in case of any discrepancy, coordinate with the origin office to correct the documents timely to avoid any customs penalty and inconvenience to the customers at destinations.

3. Filing of customs manifest, either directly on the customs system or through a third party vendor.

4. Issuing Cargo arrival notices to the consignees, so that they can file the import declaration timely with the customs, for clearance of their goods.

5. Coordinating with the CFS and the carrier for collection of documents, cargo release and arrange delivery of the containers, and return empty container back to the carriers.

6. Invoicing the customers and closure of file, as per the internal KPI's

The process for the FCL is similar to LCL import except that for FCL customers, they have the choice to receive the container at their factory premises to deliver and return empty container to the carrier yard once they have devanned the cargo contents.

\subsection{Export Department}

LCL Exports operations have more workload as compared with the imports. For LCL export operations, team has the following responsibility (see Appendix C).

1. Preparing Export Tariff rate card and share with sales before updating into the system.

2. Creating Sailing schedule in the system, and share with customers on request.

3. Receiving bookings from customers, and depending on the date of cargo receiving date, assigning the shipment to a particular sailing date and provide the booking to customers accordingly.

4. Coordinating with the carrier and customer or customer appointed customs broker to

a. Follow up on booking confirmation

b. Confirm with CFS for cargo receipt.

c. Arrange container (equipment such as $20^{\prime}$ or $40^{\prime}$ ) based on the total volume,

d. Place booking with carriers, 
FCL export process is similar to LCL export process except that shipper has an option to load the container at their factory and send the loaded container straight to the port for vessel loading.

\subsection{Accounting Department}

Accounting Department in ECU has similar function as any other company. They are responsible for accuracy of financial reporting and compliances as well as following up with customers for payment and also to ensure payment to vendors as per agreed credit terms.

\section{Current challenges facing Freight consolidation industry}

- Multiple shippers and multiple consignees sharing a single container - complete cargo information, documentations and filing requirements are needed to ensure smooth clearance at destination. If there are any issues with any shipment from this container, the whole container will be delayed and all other shipments will also be affected.

- Different ways of classifying cargoes namely, General Cargo and Dangerous Goods (DG) Cargo - different countries classified their cargoes differently and a lot of time are spent communicating between loading and discharge port on what can or cannot be handled in a single container. The carrier also needs to determine whether the DG can be loaded on the vessel or aircraft.

- Cargoes come in different shapes and sizes - how to utilise the container space to achieve optimal storage since cargoes come in different sizes and heights.

- Changes in regulations in every origin, destination or within the shipping industry while aligning with the new rules in each country requires constant amendments to the shipping community. 
- Involvement of different parties in handling the cargo throughout the shipping process - no realtime end to end visibility for different parties to update the status of the cargoes.

\subsection{Assessing the potential of Blockchain Technology}

During the brainstorming session with ECU managers to assess the potential of Blockchain to transform their businesses, the following ideas were captured for consideration:

- One of the core principles of blockchain is inclusiveness. As long as their supply chain partners can participate in the blockchain, the technology will enable all its partners to update the status of each shipment. The number of parties involved in the movement of a shipment should be considered as an opportunity rather than an impediment. Blockchain can thus help to simplify traditional processes and workflows in this industry.

- Blockchain technology can digitalize the relevant shipping documents and make transactions and processes more secure and transparent to the stakeholders. This will reduce data entry by multiple parties and provide distributed ledger for all the parties related to a shipment. By allowing multiple parties to track a single transaction, blockchain can bringing in high accuracy, security and authenticity in validating transactions. Customers can now track their cargo with real time update and plan their production and sales cycle more effectively. Examples of tracking activities includes: Recording the quantity and transfer of assets like pallets, trailers, containers to each country and tracking of SKU leading to better decision making.

\subsection{Potential challenges for ECU to adopt Blockchain}

During the brainstorming session, the following challenges were surfaced:

- ECU uses multiple vendors including Port terminal operators, customs, warehouse, truckers, back-office operators. For Blockchain to work well, every operator must update the status at every touch point for the entire shipment. Currently, ECU can initially implement Blockchain with their customer and slowly roll out to other operators in the value chain. The ultimate benefits can only be realized if the technology is adopted by all relevant stakeholders.

- Data silos are the biggest roadblock in the logistics industry. Even though the industry is automating its processes, some of the processes are manual and unpredictable especially from customs, transporters and warehouses operators in underdeveloped countries. There seems to be need of change in mindset to reduce the reluctance in sharing data across organizations in order to bring more efficiency and transparency in using Blockchain. 
- ECU needs to recover the cost of implementing Blockchain in 3 to 5 years to be viable. Blockchain is still at adoption stage and players like Maersk or Walmart are still waiting to realize its full potential. Should they wait till it is matured?

- Lack of motivation for the industry to adopt new technology. With intense competition in this industry and customers demanding for lower freight costs, the motivation to adopt new technology with additional costs is least in their priority since there is considerable investment which each stakeholder needs to commit.

\subsection{Proposed Blockchain for ECU Worldwide}

Based on the key ability of Blockchain to set user permissions, existing literature identified four Blockchain typologies that determine whether the Blockchain is public or private and permissionless or permissioned (Pilkington, 2015; Morabito, 2017; Walport, 2016):

- Public permissionless Blockchain: A network in which there are no restrictions on who can read, write and validate data on the Blockchain. These participants are not necessarily known or trusted. Examples include Bitcoin and Ethereum.

- Public permissioned Blockchain: A network in which there are no restrictions on who can read or write data on the Blockchain. However, there are restrictions on who can participate in the consensus process.

- Private permissionless Blockchain: A network in which there are restrictions on who can read and write data on the Blockchain. However, there are no restrictions on who can participate in the consensus process.

- Private permissioned Blockchain: A network in which there are restrictions on who can read, write and validate data on the Blockchain. When these networks involve more than one organisation, the network is known as a Blockchain consortium.

In order to promote transparency and integrity of the information, we proposed a decentralised system where the consensus mechanism is distributed across the entire network, such as in public permissionless or private permissionless blockchains to increase the shipment transparency. There are three common consensus mechanisms (Morabito, 2017; Pilkington, 2015; Matilla, 2016; Baliga, 2017) that ECU can consider for Blockchain: 
- Proof-of-Work: As seen with Bitcoin and other permissionless Blockchain networks, the chain with the most historical validation is accepted as the valid ledger by solving mathematical hashing computation with CPU power. It provides strong immutability of record at the cost of high energy consumption.

- Proof-of-Stake: With Proof-of-Stake, validators must attain ownership of a certain percentage of scarce tokens to become the dominant node in the permissioned or permissionless Blockchain network and determine the valid ledger. As an alternative to Proof-of-Work, Proof-of-Stake engages in mathematical hashing computation only in limited search space. As a result, transactions are processed faster (higher transaction per second or TPS) and the system is more energy efficient.

- Practical Byzantine Fault Tolerance: This consensus mechanism is used with permissioned Blockchain networks, such as Hyperledger Fabric. This mechanism assumes that the group of participants is known, registered and verified within the Blockchain consortium. The underlying algorithm is designed to validate the ledger once a considerable amount of node responses is signed, eliminating the energy costs associated with hashing protocols. This consensus mechanism is typically supported by business networks.

We recommend that the blockchain employs the consortium consensus mechanism or similar interoperable consensus mechanism to reduce the processing time and costs. A conceptual framework is proposed by the authors using Blockchain technology with smart contract for ECU and their supply chain partners as shown in Figure 3. 
Figure 3: Blockchain with smart contract for the shipping industry, Source: (Authors)

The purpose and the novelty of the framework is to capture relevant information directly from the source and record into the Blockchain. The proposed Blockchain will provide distributed ledgers as well as smart contracts to ensure the authentication and validity of information flow among the supply chain partners (Lu Qing and Xu Xiwei, 2017). This framework would enable real time information of each shipment to be tracked along the supply chain. The role of each actor in this consortium is as followed:

- Shippers: Prepare the shipment details and source for the carrier.

- Carrier: Publish the freight rate for each vessel and their schedule.

- ECU: Match shipper requirement with carrier schedule

- Transport operator: Update the delivery status and proof of delivery.

- Warehouse operator: Prepare the delivery note for shipment

- Customs: Approve or reject the shipment for export or import.

- Consignee: Update the delivery status upon receiving the shipments 


\subsection{Discussion and Findings}

In this case study research, smart contracts are recommended to set up at critical points along the shipment route namely the storage, customs, carrier and transporters to validate the process. Smart contracts are computer programs or codes that automatically execute when predefined conditions are met and are designed to automate much of the contractual process without any central authority or human involvement. Business rules such as Incoterms from ICC and payment terms such as Letter of Credit can also be coded using smart contract to automate the document verification process.

The shippers first request shipment order to ECU worldwide and then ECU will search for suitable carrier based on the shipper delivery schedule. Once a match is found, ECU will confirm the carrier with the shippers before booking the storage space for the cargoes and upload the cargoes' details into the Blockchain (the number of shipping bill, pick up point, weight, volume, packing deadline, etc.). Using the booking information, the Blockchain will inform shipper to dispatch their cargoes to specific LCL warehouse for consolidation. The transporter will then update the delivery on the Blockchain and gets paid once the smart contract match the delivery confirmation from the carrier. Shipping details are updated by the carrier and the shipping manifest and airway bill or bill or lading will be updated into the Blockchain. Any discrepancies between the shipment amount between delivery note and the bill will be rejected by smart contract and the managers will be alerted for action or approval before the shipment can continue. Similarly, the customs department will verify and approve the shipment before updating the Blockchain. Lastly, the Blockchain will automatically settles all the freight bills on a monthly basis with each operator within the process to reduce paperwork.

Smart contract can automate the payment methods such as Letter of Credit (LoC). It can eliminate the existing ineffectiveness manual LoC, abate the transaction cost and streamline business procedures. Once the exporter submits the necessary documents and update the Blockchain records, the LoC conditions are evaluated and verified by smart contract if they meet specified the agreed conditions and the whole process is automated to determine compliance or non-compliance for each case (Goyal and Varghese, 2017).

To improve the trustworthiness of the system and the confidence that the right pieces of information are gathered by the consortium, there is a role for a neutral third party to certify, audit, and/or regulate participants. ECU can take up this role during implementation. As there are many actors involved in 
this consortium, it is recommended to start the implementation from the shipper and then move upstream. As more shippers start to use the ECU platform to book for freight, these portal can partner with the upstream operators to provide end to end blockchain solutions for the freight community.

Currently, most blockchain networks operate independently from one another. The biggest challenge to interoperability is the existence of many blockchain networks that differ in parameters such as consensus models, transaction schemes, and smart contract functionality (Qing and Xu, 2017). To combat interoperability issues, there are several standardization efforts underway including the use of API. One possibility is to use existing standards in new blockchain applications. For example, IBM and Microsoft are adopting the data standards developed by GS1 to enforce interoperability in their blockchain applications for supply chain. Another option is to develop standards from scratch. For example, the Enterprise Ethereum Alliance developed a standard version of the Ethereum blockchain for businesses. This structure would provide a full tracking capabilities from shipper to consignee for full traceability. For example, ECU platform can be connected to the Customs platform which may make use of different Blockchain technology. Similarly, ECU platform can be connected to each carrier such as Maersk shipping line since they are large enough to build their own Blockchain platform for generating bill of lading, etc. This will overcome the interoperability among various blockchain networks.

With the introduction of Blockchain, some of the challenges faced in ECU will be overcome as listed in Table 1 as follows.

Table 1: Challenges faced by ECU and the use of Blockchain to overcome them

\begin{tabular}{|c|c|}
\hline by ECU Worldwide & Blockchain solutions \\
\hline $\begin{array}{l}\text { Multiple shippers and multiple consignees } \\
\text { sharing a single container - complete cargo } \\
\text { information, documentations and filing } \\
\text { requirements are needed to ensure smooth } \\
\text { clearance at destination. }\end{array}$ & $\begin{array}{l}\text { Blockchain with distributed ledger capability } \\
\text { will provide complete transparency with full } \\
\text { documentation recorded from all the shippers } \\
\text { and consignees for each container. }\end{array}$ \\
\hline $\begin{array}{l}\text { Different ways of classifying cargoes } \\
\text { namely, General Cargo and Dangerous } \\
\text { Goods (DG) Cargo - different countries } \\
\text { classified their cargoes differently and a lot }\end{array}$ & $\begin{array}{l}\text { Smart contract can be coded for each country to } \\
\text { set the criteria for General Cargo and } \\
\text { Dangerous Cargo classification. }\end{array}$ \\
\hline
\end{tabular}




\subsection{Implications with the new blockchain system for ECU and the shipping community}

As the shipping industry involves the whole supply chain, this will ensure the needs of all the parties involved in this industry is fully understood from national and international perspective (Kshetri 2018). As small and medium size businesses will require time and significant investments to migrate to a blockchain system, one potential solution under discussion is for a shipping association to fund the blockchain infrastructure and provide a Cloud-based system that small businesses could subscribe to. This will lower their barriers to adopt the Blockchain system and motivate more SMEs to sign up for the platform.

As data shared on blockchain is tamper-evident and accessible to those that have the right permission to see it, the consortium should consider what type of data should be on-chain, what data need to be accessed by whom, for how long and for what purpose, and what data should be limited to one-toone transactions. Although many studies and research shows that blockchain is safe in every aspect, some studies shows that blockchain is still hard to ensure complete privacy and create more opportunities for hackers. A shared ledger system like blockchain can open a gate that may leak the user's information (Barcelo, 2007; Kshetri, 2018). 
Moreover, because blockchains are deemed immutable, correcting inaccurate or fraudulent data can be onerous. Any inaccurate data being input into the blockchain record would be highly costly for the whole supply chain. This is directly related to human error of which despite the accuracy of data and information flow, the logistics process is still vulnerable to human error which could cause an increase in rejection rates of process outcome. This form of security risk is obviously the key consideration for the shipping industry (Pandey et. al. 2020; Wang et al. 2014) and thus requires the increase in legal department expertise to conduct due diligence.

Our proposed blockchain based system are crucial for stakeholders' ability to reap the benefits of this transformation without risking a loss of information. Particularly those at the centre of the supply chain, such as carriers and ECU Worldwide, will see vast gains through digitization, whereas smaller entities further up and downstream need additional incentives to join (Akter et al. 2019). Reallocation of benefits might thus be necessary to contemplate when introducing a blockchain based system. Most importantly, our research finds that blockchain will have profound implications for authorities such as customs and the banks. The proposed solution would offer compelling advantages, which could streamline operations while making it more complex to conduct fraudulent commerce. When it comes to the 'containerization' of shipping documentation and a second revolution in maritime shipping, we argue that blockchain technology has the potential to transform the industry for advancing international trade in the 21 st century.

\subsection{Conclusion}

Blockchain technology has a great impact on the future of freighting and logistics industry. By creating immutable and decentralized ledgers in a peer-to-peer network which has risk of failure even in single point is the main recommended feature of blockchain technology. Primary advantage of this feature is that the information shared in the Blockchain is high secured and it can be accessed to multiple participants. Shared information is cannot be hacked or modified by anyone. Transparency and security are the two important milestones of lifecycle of transactions within the blockchain network.

\subsection{Practical contributions}

The authors have recommended the use of blockchain technology with smart contract which will overcome some of the challenges facing ECU Worldwide today. The new system is able to provide end to end visibility of the cargoes with full transparency for their supply chain partners. Blockchain technology effectively resolves these challenges with highly secured peer-to-peer network. Through 
blockchain network, ECU Worldwide customers can rely on a more transparent and secured trading system globally with the potential to enforce Incoterms using smart contract.

\subsection{Theoretical contributions}

The study highlights the following theoretical contributions. Firstly, the theoretical grounding of this research is based on Technology Acceptance Model (TAM) proposed by Davis (1989), Davis et al. (1989) and Davis (1993). Because adoption of blockchain technology is depend upon factors such as perceived ease-of-use, firm's preparedness, subjective norms, level of awareness, perceived usefulness and attitude towards actual system usage (Ryoo and Koo, 2013). Early adoption of technologies has barriers from different firm perspectives (de Souza et al. 2011) however when such technologies are rightly planned with the framework and architecture behind, major technological adoption barriers could be eliminated (Sundarakani et al. 2012). In that perspective, the second major theoretical contribution of this research revolves around the proposed theoretical framework contribution of blockchain adoption for private and public firms in logistics industry.

\subsection{Limitations and future research}

Future researches can further exploit the shipping industry by developing end to end Blockchain system for exporting and importing global process using smart contract with machine learning capability. While there are numerous researches being conducted in machine learning for the shipping industry, there are few researchers that attempt to examine how machine learning can interface with smart contract so that the business rules can be set dynamically as the behaviour changes overtime. Since there are high shipping transactions globally, machine learning can learn from the buying behaviour and change some of these rules dynamically to achieve higher profitability.

This research paves the way for further extension and studies in broader scale with a particular explanation in each specific tasks of shipping process. Moreover, the future research can conduct a deeper research on design principles so as to examine under which conditions adoption would be favoured. Another point also needs to be mentioned in the future research is the operation staff and engineering of this adoption. Since this framework requires more parties and the complicated combination of blockchain, IoT, and smart contract, it is perplexing to scale up this system. Thus, future research can investigate into how the operational staff and engineers can cooperate with each other to enhance the stability of the system. 


\section{Acknowledgements}

The authors also wish to thank Mr Uday Shetty, COO of ECU Worldwide and his regional managers for sharing their view on the current process for freight booking and their view on potential Blockchain development for the industry.

\section{Disclosure statement}

No potential conflict of interest was reported by the authors. 
Appendix A- Questions prepared for Focus Group Discussion with ECU country managers

1. Identify challenges of shipping complex cargo especially LCL cargo. What can be sources of competitive advantage for ECU over your competitors. How can this be achieved thru what is described in question 2-5 below.

2. What is customer delight in LCL/FCL business- how is it linked to innovation, agility and business model?

3. What different would it make to transform the import and export processes using blockchain technology?

4. How can Accounts, HR, Marketing support blockchain system if any?

5. Any plan to implement or to delay in in using blockchain technology? What are the uncertainties that concern you in using blockchain today? 
Appendix B - Import LCL Process, Source: Authors
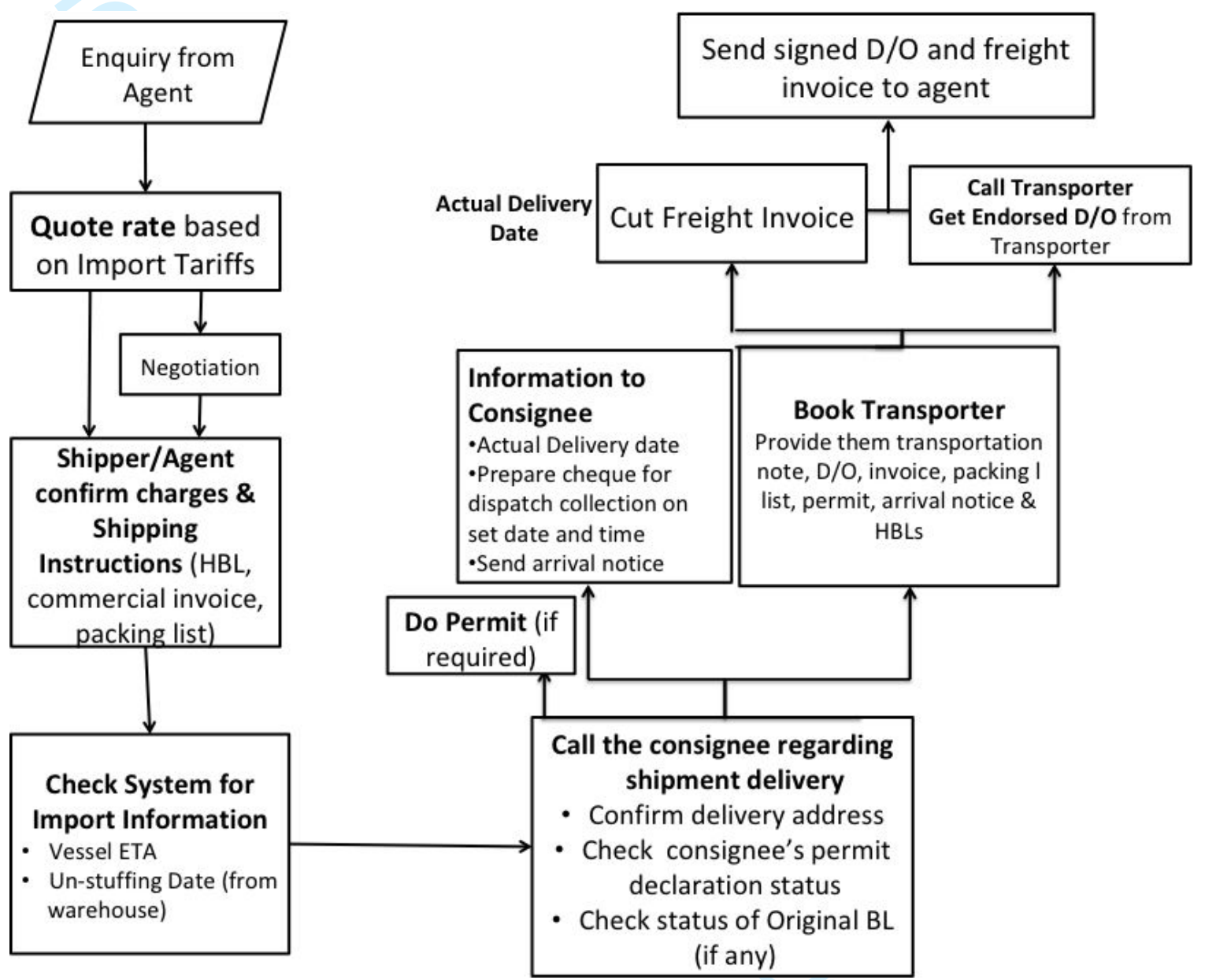
Appendix C- Export LCL Process, Source: Authors

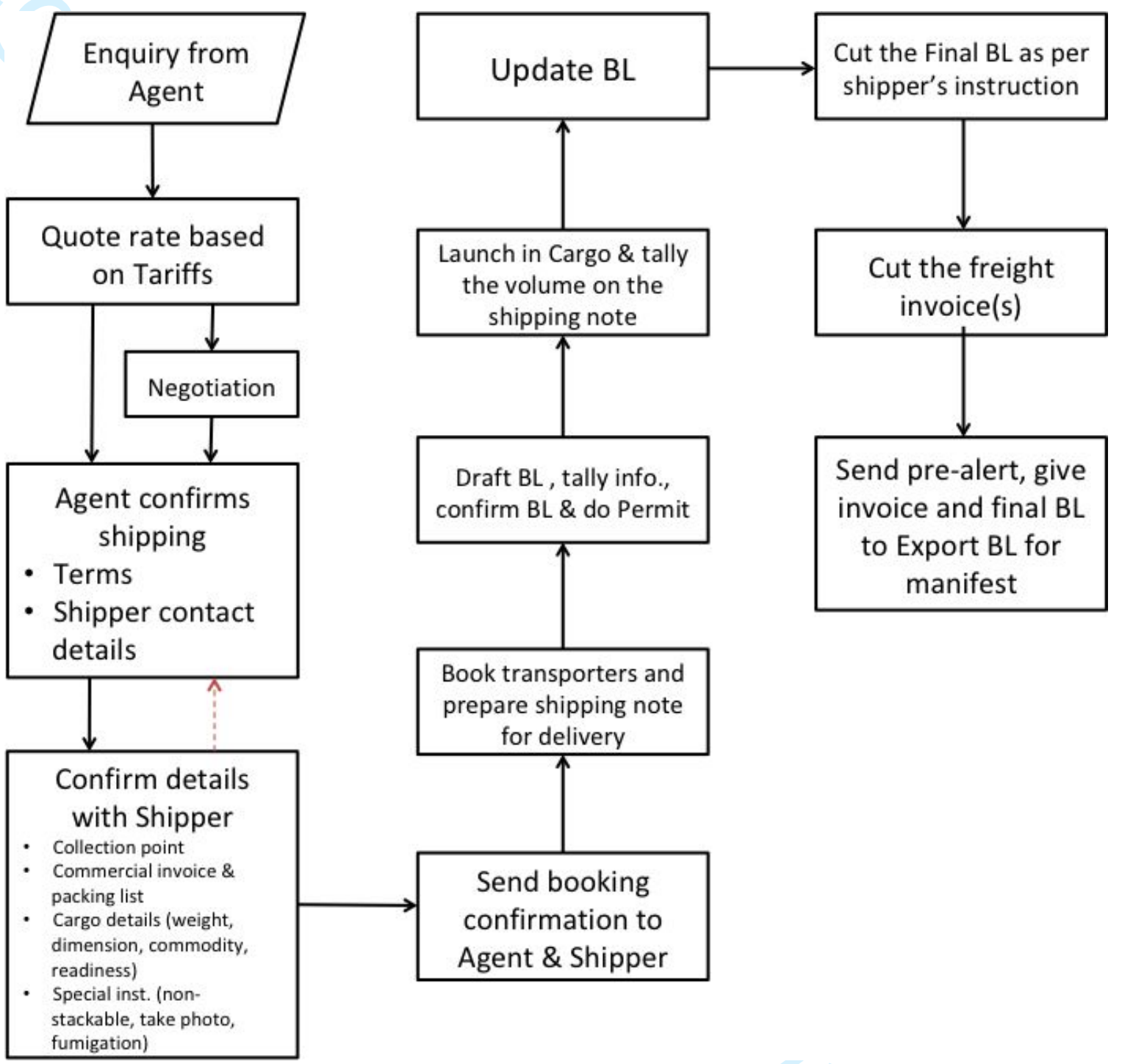




\section{References}

Akter, N., Chhetri, P. and Rahman, S. (2019), "Understanding the usage patterns, practices and decision process of third party logistics outsourcing in Bangladesh", Journal of Global Operations and Strategic Sourcing, Vol.12, No.3, pp.329-354

Anders, V. H. and Jorgen, S. N. (2017), "Blockchain enabled trust \& transparency in supply chains”, NTNU School of Entrepreneurship, Master Dissertation. pp.230

Badzar, Amina. (2016), "Blockchain for Securing Sustainable Transport Contracts and Supply Chain Transparency.” Department of Service Management and Service Studies, Master Thesis, Lund University. Accessible at http://lup.lub.lu.se/luur/download?func $=$ downloadFile\&recordOId $=8880383 \&$ fileOId $=8880390$ [accessed 07 August 2020]

Banker, S. (2016), “Will blockchain technology revolutionize supply chain applications”, Accessible at https://logisticsviewpoints.com/2016/06/20/. [accessed 07 August 2020]

Barcelo, J. (2007), "User Privacy in the Public Bitcoin Blockchain.” Journal of Latex Class Files, Vol.6, No.1, pp.1-4.

Bavassano, G., Ferrari, C., and Tei, A. (2020). Blockchain: How shipping industry is dealing with the ultimate technological leap. Research in Transportation Business \& Management, 100428, [Article in press - Accessed 07 June 2020]

Behl, A. (2020), "Antecedents to firm performance and competitiveness using the lens of big data analytics: a cross-cultural study", Management Decision, Vol. ahead-of-print No. ahead-of-print. https://doi.org/10.1108/MD-01-2020-0121[accessed 07 July 2020]

Brody, P. (2017), "How the blockchain revolutionizes supply chain management", Accessible at: $\quad$ https://www.digitalistmag.com/finance/2017/08/23/how-the-blockchainrevolutionizes-supply-chain-management-05306209. [accessed 07 August 2020]

Byrne, D. \& Ragin, C. (2009), The Handbook of Case-Centered Research Methods, London: Sage Publications. Singapore.

Christidis, Konstantinos, and Michael Devetsikiotis. (2016), "Blockchains and Smart Contracts for the Internet of Things." IEEE Access, Vol. 4, pp. 2292-2303.

Chryssochoidis, G., and Theoharakis, V. (2004). Attainment of competitive advantage by the exporter-importer dyad: The role of export offering and import objectives. Journal of Business Research, Vol.57, No.4, pp.329-337. 
Clott, C., Hartman, B., and Beidler, B. (2020). Sustainable blockchain technology in the maritime shipping industry. In Maritime Supply Chains, pp. 207-228, [Article in press - Accessed 07 June 2020]

Davis, F.D. (1989), Perceived usefulness, perceived ease of use, and user acceptance of information technology. MIS Quarterly, Vol.13, No.3, pp.319-340.

Davis, F.D. (1993) User acceptance of information technology: System characteristics, user perceptions and behavioral impacts. International Journal of Man-Machine Studies, Vol.38, No.3, pp. 475-487.

Davis, F.D.; Bagozzi, R.P.; and Warshaw, P.R. (1989) User acceptance of computer technology: a comparison of two theoretical models. Management Science, Vol.35, No.8, pp.982-1003

De Souza, R., Mark Goh, Sundarakani, B., Wong T, W., Wu Yong, Keith Toh, (2011) Return on Investment Calculator for RFID Ecosystem of High Tech Company, Computers In Industry: An International Journal, Vol. 62, No.8-9, pp.820-829

ECU Worldwide (2020) Company Information, accessed from https://www.ecuworldwide.com/ [accessed 07 July 2020]

Fylaktopoulos, G., G. Goumas, M. Skolarikis, A. Sotiropoulos, and I. Maglogiannis. (2016) “An Overview of Platforms for Cloud Based Development.” SpringerPlus, Vol. 5 (1), pp. $38-45$

Fei, J. (2011). An empirical study of the role of information technology in effective knowledge transfer in the shipping industry. Maritime Policy \& Management, Vol.38(4), pp.347367.

Goldby, M. (2019). Facilitating the Transition to Paperless Trade: The Role of Single Windows. Trade Facilitation and the WTO, (Eds) Sheela Rai and Jane K. Winn, Chapter III, Cambridge publishers, UK, pp.36-55.

Goyal, Rashi, and Lata Varghese. (2017), “Blockchain for Trade Finance: Payment Method Automation." Accessible at https://www.cognizant.com/whitepapers/blockchain-fortrade-finance-payment-method-automation-part-2-codex3071.pdf [accessed on 07 Aug 2020]

IATA (2019), Air freight market analysis, Accessible at: https://www.iata.org/en/iatarepository/publications/economic-reports/air-freight-monthly-analysis-nov-2019/ [accessed on 07 Aug 2020] 
IBM (2017), Blockchain for shipping industry, Accessible at https://opensea.pro/blog/blockchain-for-shipping-industry. [accessed on 07 Aug 2020]

Ivanov, D. (2020). Predicting the impacts of epidemic outbreaks on global supply chains: A simulation-based analysis on the coronavirus outbreak (COVID-19/SARS-CoV-2) case. Transportation Research Part E: Logistics and Transportation Review, Vol.136, pp.1-14.

Jensen, T., Hedman, J., \& Henningsson, S. (2019). How TradeLens Delivers Business Value With Blockchain Technology. MIS Quarterly Executive, Vol.18, No.4, pp.1-15.

Kamble, S., Gunasekaran, A., \& Arha, H. (2019). Understanding the Blockchain technology adoption in supply chains-Indian context. International Journal of Production Research, Vol.57, No.7, pp.2009-2033

Kavussanos, M. \& Visvikis, I. (2006), "Shipping freight derivatives: A survey of recent evidence", Maritime Policy and Management: The Flagship Journal of International Shipping and Port Research, Vol.33, No.3, pp.233-255.

Kshetri, Nir. (2018), “Blockchain's Roles in Meeting Key Supply Chain Management Objectives.” International Journal of Information Management, Vol.39, pp. 80-89.

Lambrou, M., Watanabe, D., \& Iida, J. (2019). Shipping digitalization management: conceptualization, typology and antecedents. Journal of Shipping and Trade, Vol.4(1), pp. 1-17.

Lessa, J. C. C., \& Bulut, B. (2020). A New Era, a New Risk! "A Study on the Impact of the Developments of New Technologies in the Shipping Industry and Marine Insurance Market”. In InsurTech: A Legal and Regulatory View, Springer. pp. 313-342.

Levy, Karen E. C. (2017), "Book-Smart, Not Street-Smart: Blockchain-Based Smart Contracts and The Social Workings of Law." Engaging Science, Technology, and Society, Vol.3, No.1, pp.12.-23

Liu, C. L., Shang, K. C., Lirn, T. C., Lai, K. H., \& Lun, Y. V. (2018). Supply chain resilience, firm performance, and management policies in the liner shipping industry. Transportation Research Part A: Policy and Practice, Vol.110, pp.202-219.

Lubowe, D. \& McDermott, B. (2016), Trust in trade towards stronger supply chains, IBM Institute for Business Value, Copyright IBM Corporation 2016, Somers, NY. 
Mann, C. L. (2020). Real and financial lenses to assess the economic consequences of COVID19. Economics in the Time of COVID-19, p.81.

McLean, Sue, and Simon Deane-Johns. (2016), "Demystifying Blockchain and Distributed Ledger Technology - Hype or Hero?” Computer Law Review International, Vol.17, No.4, pp.97-103.

Nakamoto, S. (2018), Blockchains and distributed ledger technologies in general, accessible at https://blockchainhub.net/blockchains-and-distributed-ledger-technologies-in-general/. [accessed 23 July 2020]

Pandey, S., Singh, R.K., Gunasekaran, A. and Kaushik, A. (2020), "Cyber security risks in globalized supply chains: conceptual framework", Journal of Global Operations and Strategic Sourcing, Vol.13, No.1, pp.103-128.

Papathanasiou, A., Cole, R., \& Murray, P. (2020). The (non-) application of blockchain technology in the Greek shipping industry. European Management Journal. In-print. [accessed 07 July 2020]

Queiroz, M. M., \& Wamba, S. F. (2019). Blockchain adoption challenges in supply chain: An empirical investigation of the main drivers in India and the USA. International Journal of Information Management, Vol.46, pp.70-82

Riley, S. (2017), "Blockchain is poise to impact supply chain, Special Report", Supply \& Demand Chain Executive, SDCExec.com, AC Business Media.

Ryoo, S.Y. and Koo, C. (2013) Green practices-IS alignment and environmental performance: The mediating effects of coordination. Information System Frontiers. Vol.15, pp.799814.

Sadouskaya, K. (2017), "Adoption of blockchain technology in supply chain and logistics", Business Logistics. Accessed from https://www.theseus.fi/bitstream/handle/10024/126096/Adoption\%20of\%20Blockchain\%20 Technology\%20in\%20Supply\%20Chain\%20and\%20Logistics. pdf?sequence=1. [accessed on 07 July 2020]

Stake, E. Robert, (2006), “Multiple Case Study Analysis”, New York: Guilford Press.

Sun, J., Yan, J. \& Zhang, K. (2016), Blockchain-based sharing services: What blockchain technology can contribute to smart cities, Financial Innovation, Vol.26, No.2, pp.1-9.

Sundarakani, B., Tan, A.W.K. and Van Over, D. (2012) Enhancing the Supply Chain Management performance using Information Technology: some evidence from UAE 
companies, International Journal of Logistics Systems and Management, Vol.11, No.3, pp.306-324

Swan, Melanie. (2015). Blockchain: Blueprint for a New Economy. Sebastopol, CA O’Reilly Media.

Takahashi K., (2016), "Blockchain technology and electronic bills of lading", Journal of International Maritime Law: Law Text publishing limited, Japan

Tan, AWK, Zhao YF and Halliday T., (2018) "A Blockchain Model for Less Container Load Operations in China." International Journal of Information Systems and Supply Chain Management, Vol.11, No.2, pp.39-53.

Tan, B. S., \& Thai, V. V. (2014). Knowledge sharing within strategic alliance networks and its influence on firm performance: the liner shipping industry. International Journal of Shipping and Transport Logistics, Vol.6, No.4, pp.387-411.

Tirschwell (2018), Maersk IBM joint venture create industry blockchain pipeline, Accessible at https://www.joc.com/maritime-news/container-lines/maersk-line/maersk-ibm-joint-venturecreate-industry-blockchain-pipeline 20180116.html [accessed on 07 Aug 2020]

UNCTAD. (2017) "UNCTAD Review of Maritime Transport 2017." New York. http://unctad.org/en/PublicationsLibrary/rmt2017_en.pdf. [accessed on 07 July 2020]

Vogt, W. Paul, (2011), "Comparative case studies as an alternative to RCTs: Innovations in program evaluation", In William, M. \& Vogt, W.P. (Eds.), The Sage Handbook of Innovation in Social Research Methods, Los Angeles: Sage Press.

Wang, Grace W.Y., Su-Han Woo, and Joan Mileski. (2014), "The Relative Efficiency and Financial Risk Assessment of Shipping Companies.” Maritime Policy \& Management, Vol.41, No.7, pp.651-66.

Weber, X., Riverret, R., Governatori, G., Ponomarev, A. \& Mendling, J. (2016), “Untrusted business process monitoring and execution using blockchain", Business Process Management, BPM2016, Springer, pp.329-347.

White M., (2018), Blockchain improved visibility and inefficiencies of paper based process, accessible at https://www.ibm.com/blogs/blockchain/2018/01/digitizing-global-trade-

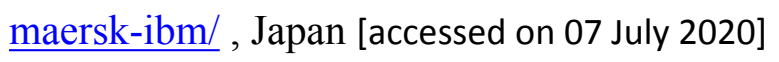


Wright, A. \& De Filippi, P. (2017), Decentralized Blockchain Technology and Rise of Lex Cryptographies, accessible at http://ssrn.com/abstract=2580664. [accessed on 07 July 2020]

Yin, K. Robert, (2014), Design and Methods: Case Study Research, (5 ${ }^{\text {th }}$ Edn.), Los Angeles, Sage Press. 